\title{
Pathways of Peptide Ion Fragmentation Induced by Vacuum Ultraviolet Light
}

\author{
Weidong Cui, Matthew S. Thompson, and James P. Reilly \\ Department of Chemistry, Indiana University, Bloomington, Indiana, USA
}

One Hundred Fifty-Seven nm photodissociation of singly protonated peptides generates unusual distributions of fragment ions. When the charge is localized at the C-terminus of the peptide, spectra are dominated by $x-, v-$, and $w$-type fragments. When it is sequestered at the $\mathrm{N}$-terminus, $a$ - and $d$-type ions are overwhelmingly abundant. Evidence is presented suggesting that the fragmentation occurs via photolytic radical cleavage of the peptide backbone at the bond between the $\alpha$ - and carbonyl-carbons followed by radical elimination to form the observed daughter ions. (J Am Soc Mass Spectrom 2005, 16, 1384-1398) @ 2005 American Society for Mass Spectrometry

$\mathrm{T}$ landem mass spectrometry (MS/MS) is a widely used technique in proteomics that is employed to identify proteins based on the fragmentation of proteolytic peptides $[1,2]$. Although a variety of excitation methods have been applied to generate peptide fragments, including blackbody radiation [3], IR multiphoton excitation [4], UV laser excitation [5-9], and collisions with gas-phase molecules [1] or surfaces [10], low-energy collisional activation is the most commonly employed technique. These methods have been reviewed recently [11].

Low-energy fragmentation appears to be well described by the mobile proton model according to which vibrational excitation of the analyte leads to charge mobility [12]. Transfer of the charge proton to either the backbone carbonyl oxygen or amide nitrogen enables charge-induced cleavage of the peptide backbone. This process yields primarily $b$ - and $y$-type fragment ions according to the standard nomenclature shown below $[13,14]$.

Higher energy activation methods involving collisions with gas molecules or surfaces can enable chargeremote fragmentation [15-17]. However, even in these cases, apparently, protonated peptides still generate some fragments through charge-directed processes [17]. Immobilization of the charge, either by using metal adducts [18] or charged chemical modifications [19-22], has been used to inhibit charge-directed fragmentation. In these cases, primarily $a-, d-$, and $w$-type fragments are observed. Several mechanisms have been proposed for charge-remote peptide fragmentation, some involving homolytic radical cleavage [14, 23].

Electron capture dissociation (ECD) [24] and the recently reported electron-transfer dissociation (ETD)

Published online June 24, 2005

Address reprint requests to Professor J. P. Reilly, Department of Chemistry, Indiana University, Chemistry Building, 800 E. Kirkwood Ave., Bloomington, IN 47505-4001, USA. E-mail: reilly@indiana.edu
[25] appear to be nonthermal processes. These phenomena generate $c$ - and z-type fragment ions upon the addition of an electron to a multiply charged protein or peptide ion. Two mechanisms have been proposed, one involving reactions of a free hydrogen atom generated when an electron is captured by a charged site on the analyte ion [26], and the other involving localization of the $\sim 6 \mathrm{eV}$ of energy that is generated upon charge neutralization. This energy then induces fragmentation through an excited electronic state [27]. Implicit in this second mechanism is the suggestion that techniques which excite appropriate electronic states can lead to unique, nonergodic fragmentation even for molecules as large as peptides and proteins [24, 27]. This can occur if ions reach a dissociative electronic state and fragment before the energy is redistributed throughout the molecule. Electronic to vibrational relaxation, resulting in nonspecific excitation is an important competing process that often inhibits nonergodic processes, and rates of relaxation are predicted to increase with the size of the molecule [28].

Lasers are powerful tools that can also be used to excite molecules to specific energy levels with either multiphoton or single photon processes. Light is not affected by the electric or magnetic fields of mass spectrometers, so laser techniques are compatible with a wide variety of mass analyzers. In addition, light has a minimal impact on the operating conditions of the instrument compared with collision gases or surfaces. Several wavelengths of light have been used to excite peptide ions. Infrared light sources, as in blackbody infrared radiative dissociation [3] and infrared multiphoton dissociation [4], necessarily excite molecular vibrations leading to charge-induced fragmentation. Ultraviolet light, in particular at $193 \mathrm{~nm}$, has been utilized in a number of single photon excitation studies $[5-7,9,29,30]$. Some high-energy fragments typical of charge-remote fragmentation processes have been observed, but there is little evidence of unique photo- 


\section{$\begin{array}{lll}\text { Source } 1 & \text { Source } 2 & \text { Reflectron }\end{array}$}
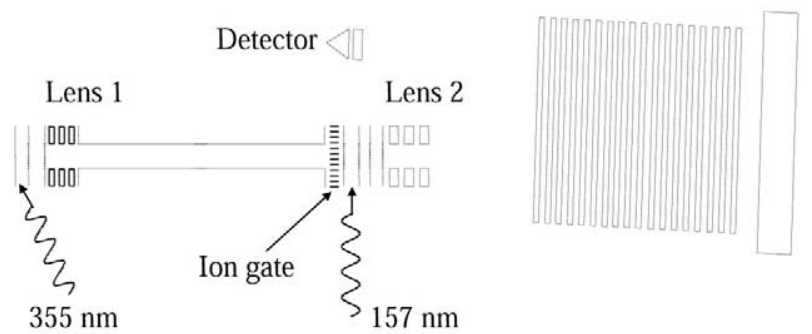

Figure 1. Tandem time-of-flight apparatus used for photodissociation experiments. Not drawn to scale.

chemistry. Results from photodissociation of peptide ions using $266 \mathrm{~nm}$ light to excite a tryptophan chromophore have also been reported recently. The fragmentation patterns in initial experiments at this wavelength do not exhibit any unusual specificity $[8,31]$.

Experimental and theoretical work has shown that small peptides have strong absorption bands in the vacuum ultraviolet associated with backbone chromophores [32]. The first band is centered around 190 $\mathrm{nm}$ [33], and is accessible with the $193 \mathrm{~nm}$ light mentioned above. The second band is centered at $160 \mathrm{~nm}$ $[34,35]$. We have used a $157 \mathrm{~nm}$ molecular fluorine laser to excite this band, resulting in a unique fragmentation pattern from singly-charged peptide ions having Cterminal basic residues [9]. In the present work, additional experiments with peptides having $\mathrm{N}$-terminal as well as C-terminal basic residues provide evidence that for both peptide types, $157 \mathrm{~nm}$ photodissociation induces cleavage via radical photolysis. Subsequent elimination processes yield the observed fragment ions. Photodissociation results are different from those obtained with high-energy CID in experiments involving similar ion excitation energy.

\section{Experimental}

Experiments were performed on a homebuilt MALDI tandem time-of-flight instrument, shown schematically in Figure 1. The design of the instrument is generally similar to tandem time-of-flight instruments that employ collision cells $[36,37]$ except that ion fragmentation is induced by $157 \mathrm{~nm}$ VUV light from an $\mathrm{F}_{2}$ laser. MALDI ions are generated in source 1 by irradiating the spot with $\sim 10 \mu \mathrm{J}$ of $355 \mathrm{~nm}$ light from a Nd-YAG laser (GCR-2A, Quanta-Ray, Mountain View, CA). This light is detected by a photodiode and triggers the two delay generators used to control ion extraction pulses in each stage, the ion gate, $\mathrm{F}_{2}$ laser and digitizer (Models 4070 and 555, Berkeley Nucleonics, San Rafael, CA). Precursor ions are first separated in a $30 \mathrm{~cm}$ linear flight tube. At the end of this stage, a wire comb ion gate selects a mass of interest. For $157 \mathrm{~nm}$ photodissociation, an unfocused $10 \mathrm{~ns}, 1 \mathrm{~mJ}$ light pulse with a $5 \mathrm{~mm} \times 10 \mathrm{~mm}$ cross section (EX100HF-60, GAM Laser, Orlando, FL) crosses the ion path at an appropriate time to interact with the selected ions. Precursor and fragment ions are then reaccelerated in source 2 , separated over a $2 \mathrm{~m}$ flight path in the second stage reflectron TOF and detected by a dual microchannelplate detector. The anode signal is amplified [38] and recorded with a fast waveform digitizer (DP210, Acqiris, Monroe, NY) controlled by custom software. Post-source decay (PSD) fragments are formed during transit through the first flight tube. These fragments travel through the first stage with the precursor ions to the source of the second stage where they are reaccelerated and separated. To make it possible to distinguish PSD fragments from those formed by photodissociation, the $\mathrm{F}_{2}$ laser is triggered on alternate shots, and spectra with and without the photodissociation laser are averaged separately. The result is one dataset that contains only PSD fragments, and a second that contains both PSD and photodissociation fragments. Since these spectra are recorded quasi-simultaneously, any slow fluctuations in the MALDI ion production will affect both equivalently, and the PSD contribution to the two spectra will be essentially identical. To isolate the photofragmentation contribution, the two spectra are subtracted. Since PSD products drift with precursor ions in the first stage of the instrument, some of them may also be photodissociated. In most experiments, precursor ion signals are allowed to exceed the digitizer range. To determine the probability that any of the observed fragments were formed from a PSD product precursor, specific experiments in which the digitzer range was increased were performed to measure the photodissociation efficiency. Spectra were smoothed via 7 point FFT smoothing (OriginPro) and mass calibration was performed with software developed in-house. Low-energy CID was performed on a Thermo Electron LCQ Deca XP (Waltham, MA) using an atmospheric pressure MALDI ionization source. High-energy CID data were recorded on an Applied Biosystems (Foster City, CA) 4700 Proteomics Analyzer using $2 \mathrm{keV}$ fragmentation energy with air as the collision gas.

Angiotensin II, Substance P, trypsinogen, carboxypeptidase $\mathrm{A}$, and human hemoglobin were purchased from Sigma-Aldrich (St. Louis, MO). Tryptic peptides were obtained by enzymatic digestion of proteins followed by HPLC purification. Guanidination of one lysine-containing peptide was performed according to the published procedure [39].

\section{Results}

\section{C-Terminal Arginine Peptides}

Many protein identification strategies involve MS/MS experiments on tryptic peptides [40]. For this reason, we have chosen tryptic peptides and their analogs, all having C-terminal basic residues, as our initial target molecules. We have previously reported several exam- 
(a)

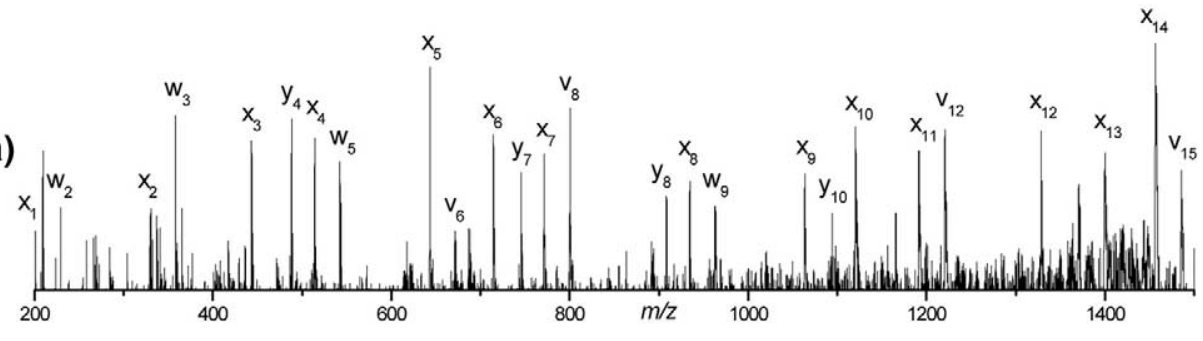

(b)

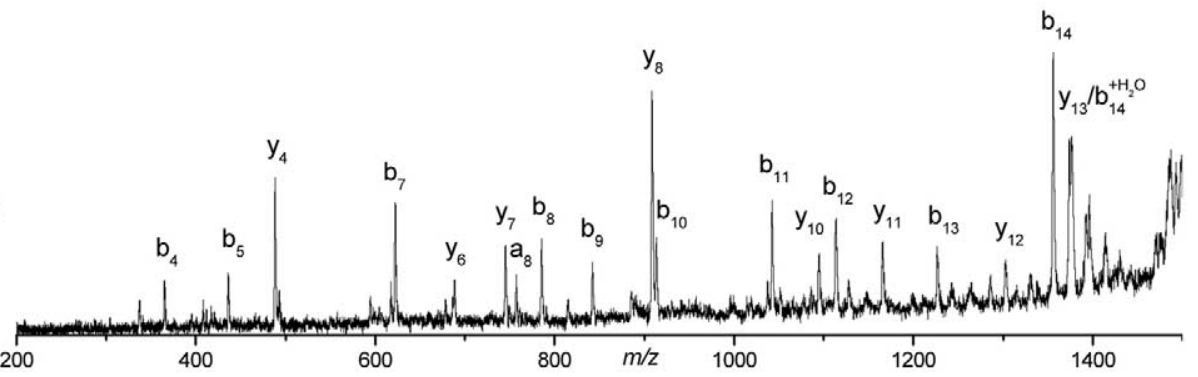

(c)
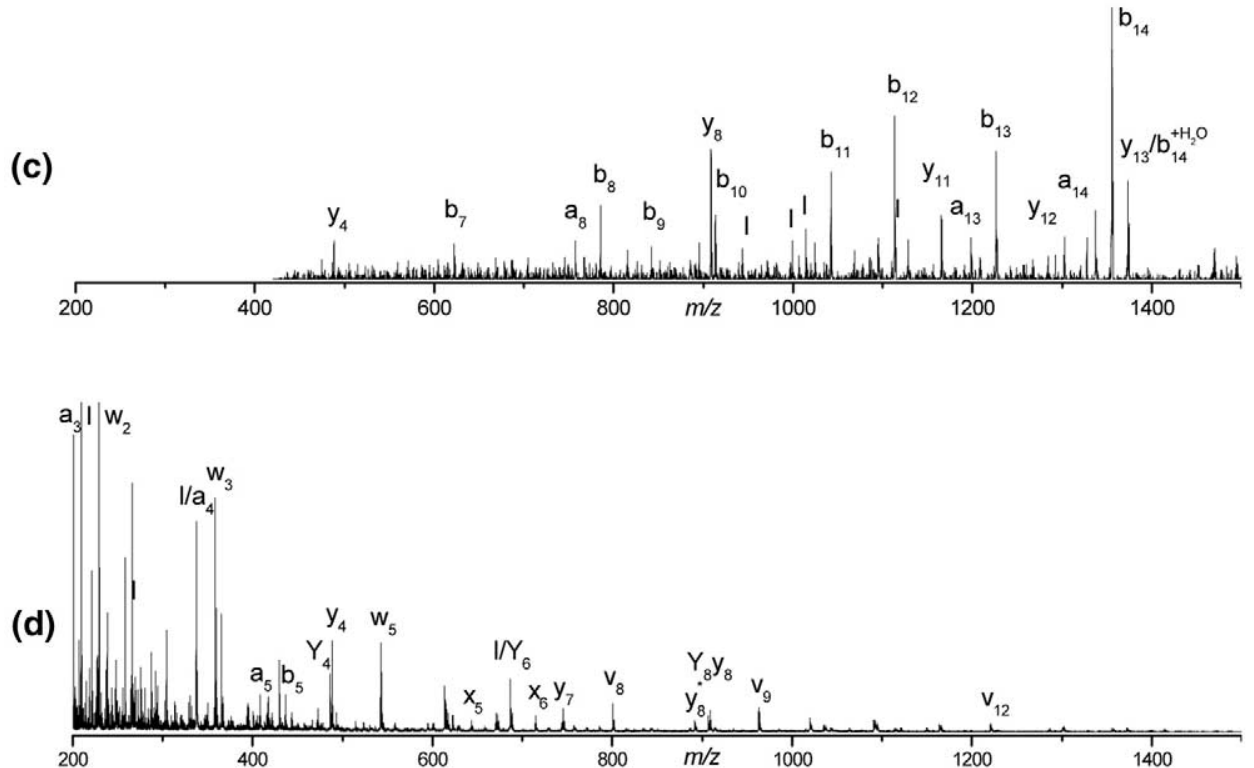

Figure 2. Tandem mass spectra of the singly charged hemoglobin tryptic peptide VGAHAGEYGAEALER obtained by (a) $157 \mathrm{~nm}$ photodissociation, (b) post-source decay, (c) ion trap CID, (d) $2 \mathrm{keV}$ CID.

ples [9], and will present results from other molecules here.

Figure 2a shows typical results from the $157 \mathrm{~nm}$ photodissociation of the arginine-terminated hemoglobin tryptic peptide VGAHAGEYGAEALER. The 157 $\mathrm{nm}$ photodissociation mass spectrum of this 15 residue peptide is dominated by a series of $x$-type ions extending from $x_{1}$ to $x_{14}$. Within this fragment series, most of the ions are of roughly similar intensity. As shown in Scheme 1, $x$-type ions result from a backbone cleavage between the $\alpha$-carbon and carbonyl-carbon, with the charge retained on the C-terminal fragment. Several $v$ and $w$ ions that involve additional side-chain cleavages are also observed. Mechanisms for the formation of these fragments will be presented below. Besides these unusual fragments, four $y$-type ions are also present in this spectrum. PSD and CID experiments with this same molecule, shown in Figure $2 \mathrm{~b}$ and $\mathrm{c}$, generate mainly $b$ and $y$-type ions, but no $x$-, $v$-, or $w$-type ions. The spectra obtained by PSD and CID are quite similar to each other, as would be anticipated if precursor ions were vibrationally excited in both cases. High-energy

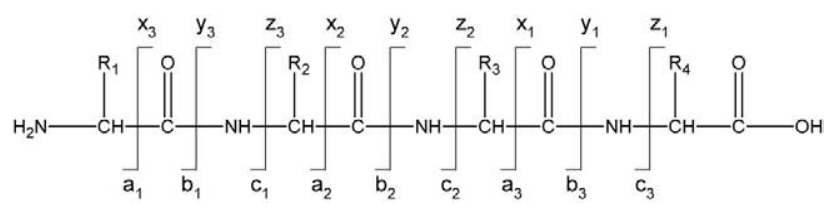

Scheme 1. Standard nomenclature for peptide ion fragments. 

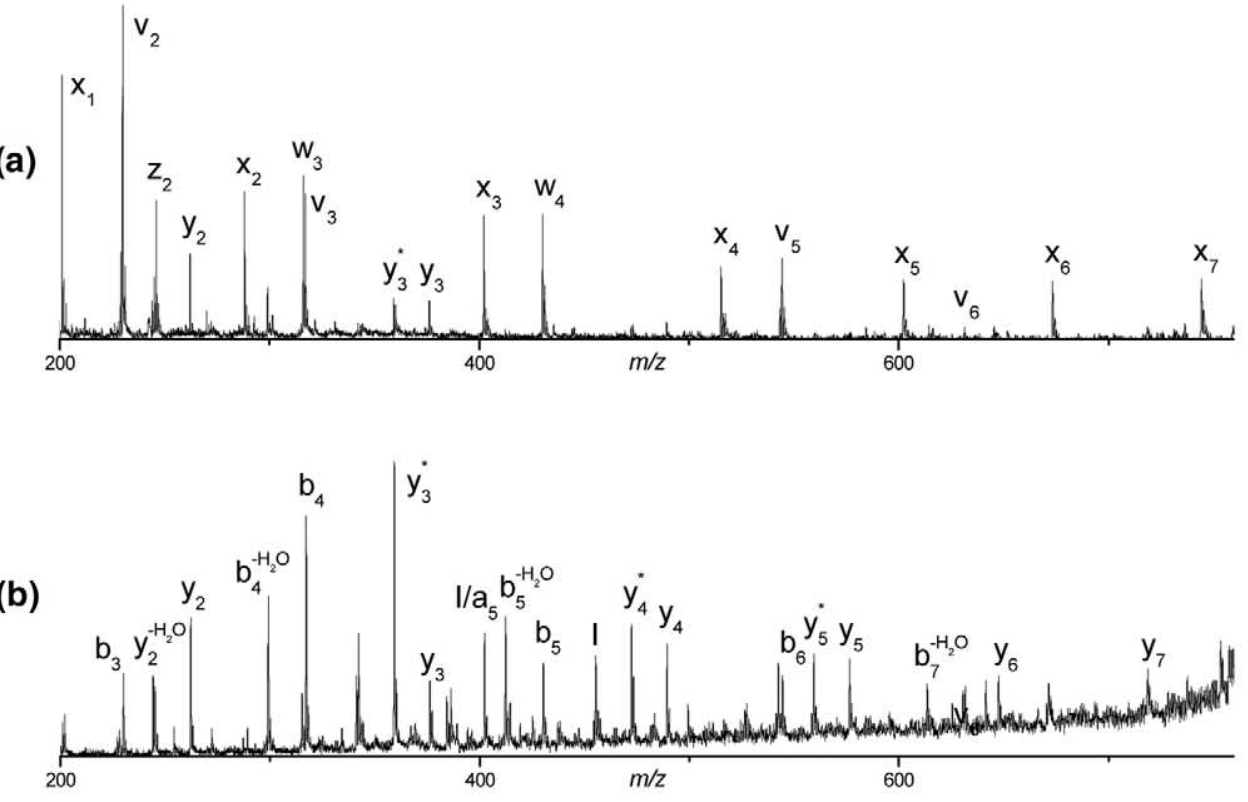

(c)
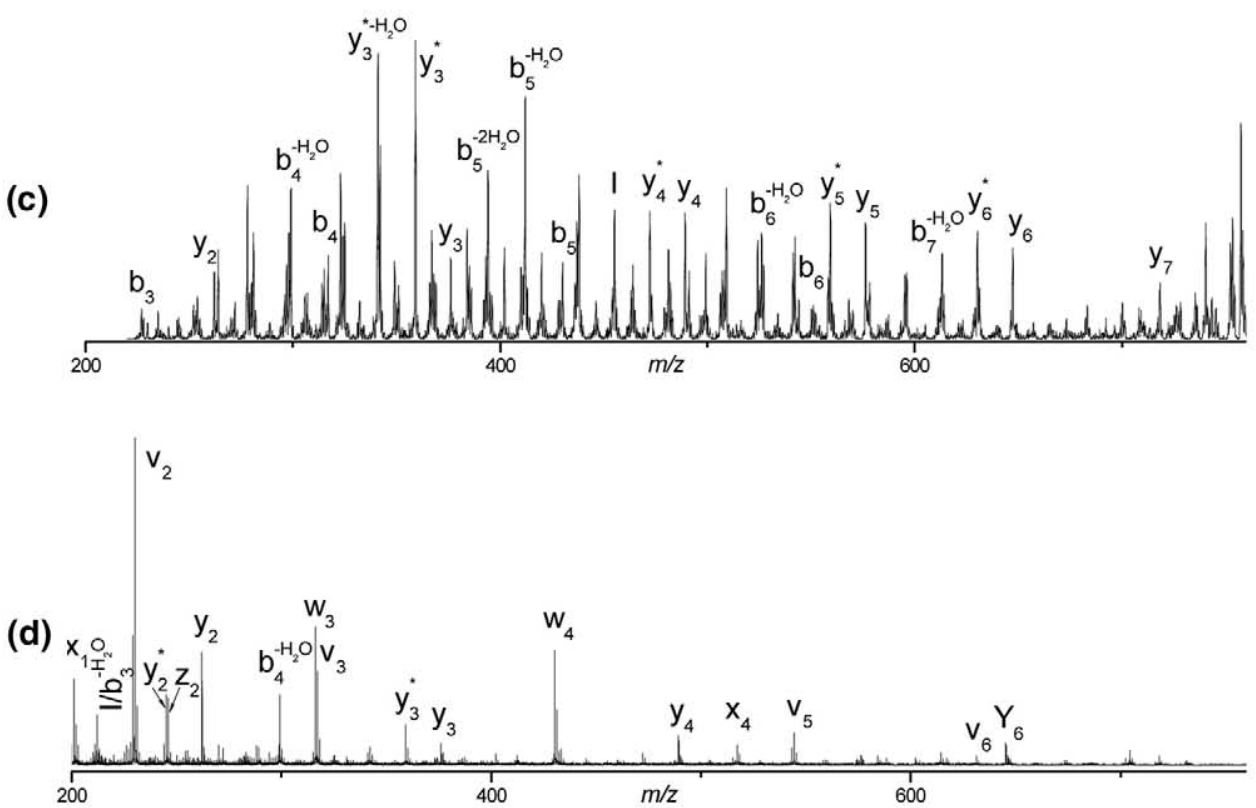

Figure 3. Tandem mass spectra of the singly charged trypsinogen tryptic peptide SAASLNSR obtained by (a) $157 \mathrm{~nm}$ photodissociation, (b) post-source decay, (c) ion trap CID, (d) $2 \mathrm{keV}$ CID.

CID (Figure 2d) produces more types of fragment ions than the other techniques. C-terminal $y, Y, x, w$, and $v$ ions as well as N-terminal $a$ and $b$ ions are observed. No more than four members of any ion series are present. The fragmentation pattern obtained with $157 \mathrm{~nm}$ photodissociation of this peptide is clearly unique.

Tandem mass spectra from another molecule having a C-terminal arginine residue, the trypsin autolysis peptide SAASLNSR, are shown in Figure 3. Again, the $157 \mathrm{~nm}$ photodissociation spectrum (Figure 3a) shows a strong series of $x$-type ions extending from $x_{1}$ to $x_{7}$. Several $v$ - and $w$-type ions accompany the $x$ ion series. The PSD (Figure 3b) and low-energy CID (Figure 3c) spectra of this molecule display a mixture of primarily $b$ - and $y$-type fragments, including many peaks resulting from the neutral loss of water or ammonia. The high-energy CID spectrum (Figure 3d) generates a few of the same $x, v$, and $w$ fragments as are produced by photodissociation. However, many are missing, and a number of $b$ and $y$ ions not present in the photodissociation data are observed.

\section{N-Terminal Arginine Peptides}

The observation of predominantly C-terminal fragment ions upon $157 \mathrm{~nm}$ photodissociation of peptides con- 
(a)

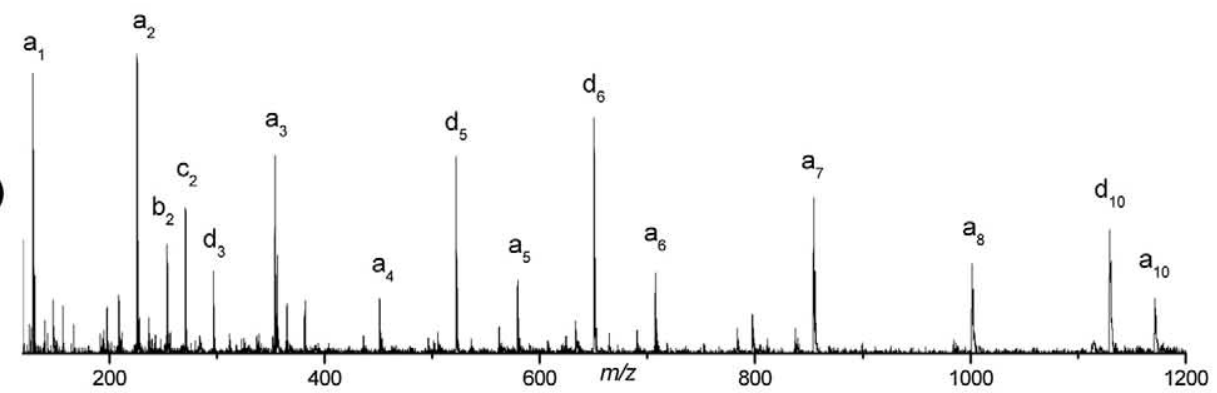

(c)
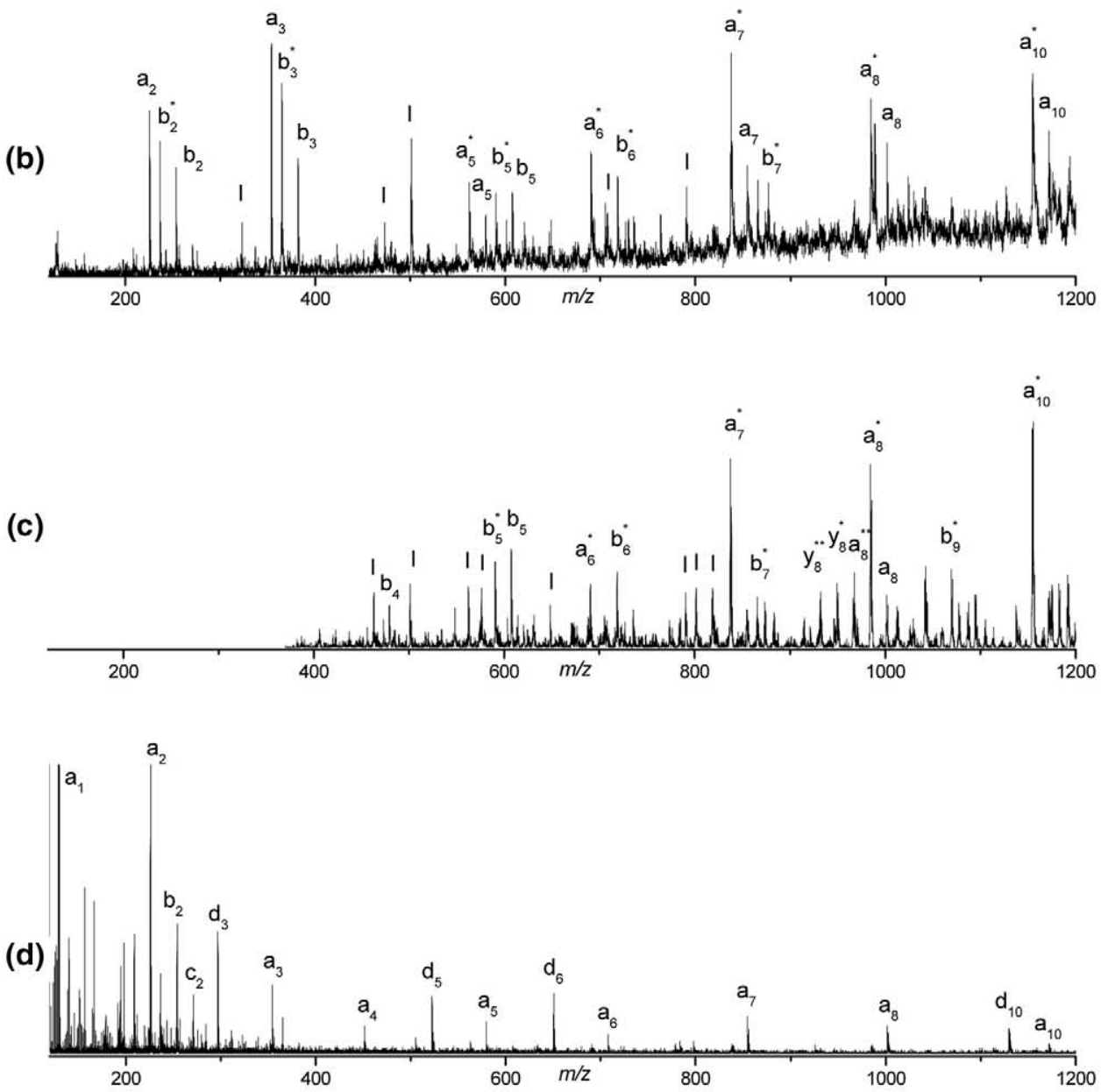

Figure 4. Tandem mass spectra of the singly charged Substance P (RPKPQQFFGLM-NH $\left.{ }_{2}\right)$ obtained by (a) $157 \mathrm{~nm}$ photodissociation, (b) post-source decay, (c) ion trap CID, (d) $2 \mathrm{keV}$ CID.

taining a C-terminal arginine residue suggests that the location of the basic site plays an important role in determining what fragments are observed. To test this hypothesis, a series of peptides having arginine at their $\mathrm{N}$-terminus have been investigated.

Figure 4 shows tandem mass spectra of Substance $P$ (RPKPQQFFGLM-NH ${ }_{2}$ ) obtained with (Figure 4a) $157 \mathrm{~nm}$ photodissociation, (Figure $4 \mathrm{~b}$ ) post source decay (PSD), (Figure 4c) low-energy collision-induced-dissociation, (Figure 4d) high-energy collision-induced-dissociation. $157 \mathrm{~nm}$ photodissociation generates a fragment pattern dominated by $a$ - and $d$-type ions. As shown in Scheme $\mathbf{1}$, $a$-type fragments result from cleavage of the $\alpha$-carbon carbonyl-carbon bond with the charge retained on the $\mathrm{N}$-terminal fragment. This is the same backbone cleavage that forms $x$-type ions when the charge is on the Cterminal fragment. The $a$ ion series obtained from this molecule extends from $a_{1}$ to $a_{10}$, although the $a_{9}$ ion, associated with cleavage adjacent to glycine, is missing. A number of $d$-type fragments are also observed. These are $\mathrm{N}$-terminal fragment ions involving an additional sidechain cleavage. PSD and low-energy CID fragmentation of this peptide generate a number of internal, $a-, b-$, and $y$-type ions as well as ammonia loss products. While some 

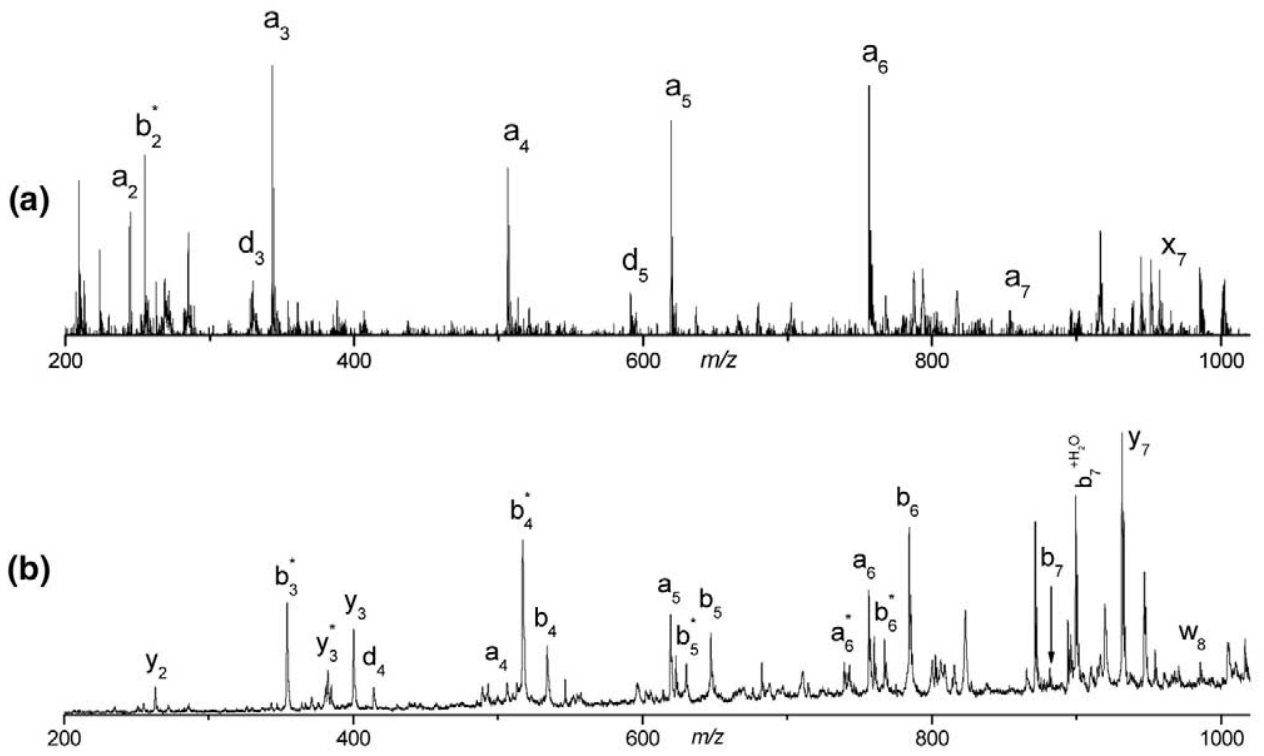

(c)
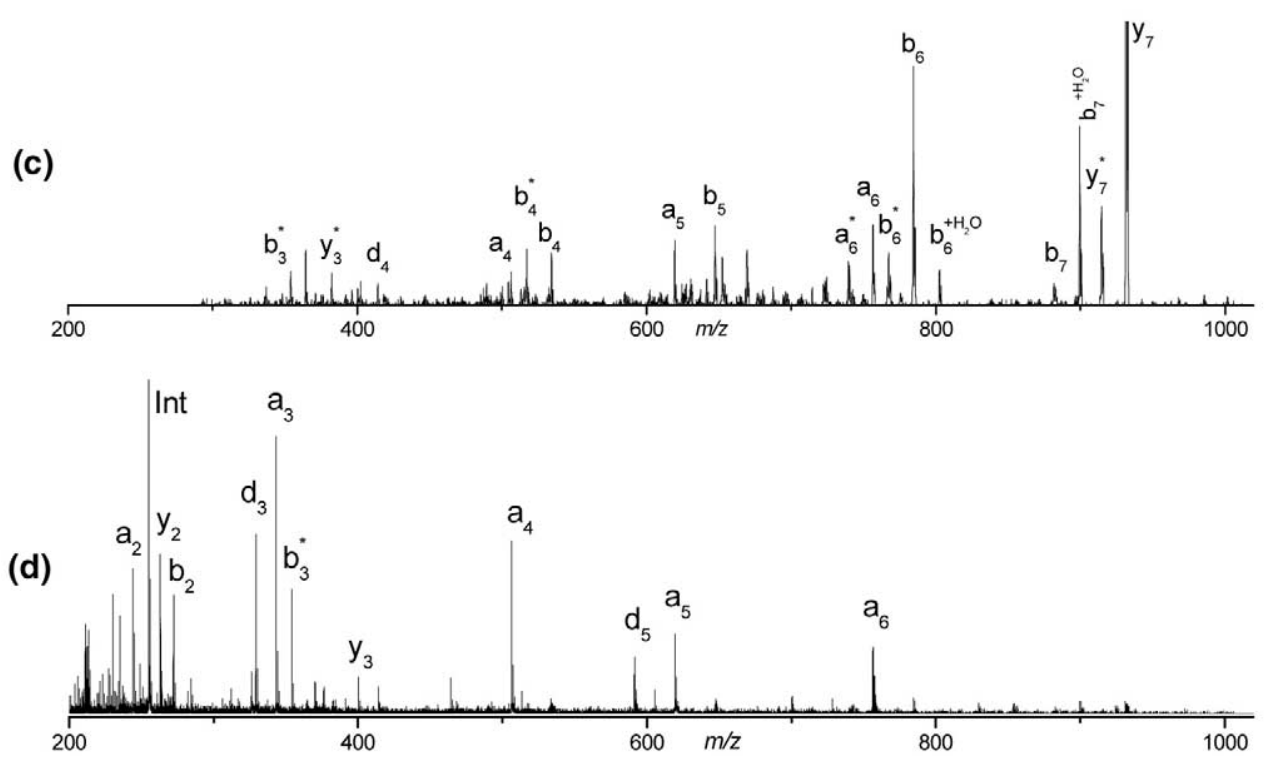

Figure 5. Tandem mass spectra of the singly charged peptide DRVYIHPF obtained by (a) $157 \mathrm{~nm}$ photodissociation, (b) post-source decay, (c) ion trap CID, (dD) $2 \mathrm{keV}$ CID.

of the same $a$ ions are present in all three spectra, the overall fragment distributions are quite different. With low-energy CID and PSD, the $a$-type ions are frequently accompanied by $a-\mathrm{NH}_{3}, b$ and $b-\mathrm{NH}_{3}$ fragments that are not observed in the photodissociation experiment. The high-energy CID spectrum of this molecule shows some similarity to the $157 \mathrm{~nm}$ photodissociation, and is also consistent with literature results [14]. A more detailed comparison will be made below.

Figure 5a shows the $157 \mathrm{~nm}$ photodissociation tandem mass spectrum of a peptide with a basic site near the N-terminus: Angiotensin II (DRVYIHPF). a-type ions ranging from $a_{2}$ to $a_{7}$ are generated. These $a$ ions have similar intensities with the exception of $a_{7}$. The reduced intensity of this fragment is likely atributable to the presence of proline as the penultimate residue, as dis- cussed below. The $a_{1}$ fragment is also missing from this peptide, but $x_{7}$, corresponding to the same backbone cleavage, can be observed. This is understandable since the N-terminal residue of $a_{1}$ would be aspartic acid, while the $x_{7}$ fragment has arginine as its first residue. A number of $d$-type ions are also present in the spectrum. The PSD and low-energy CID (Figure 5b, c) spectra of this peptide show the typical mixture of $\mathrm{N}$ - and C-terminal fragments. Figure $5 \mathrm{~d}$ shows that high-energy CID fragmentation of this peptide ion generates predominantly $a$ ions along with a few $d, b$, and $y$ type ions.

\section{Lysine-Terminated Peptides}

Because of trypsin's proteolytic selectivity, it was also of interest to investigate peptides having C-terminal lysine 
residues. Results from the photodissociation of the lysineterminated tryptic peptide NWDAGFGK are presented as Figure 6a. Although lysine, a basic amino acid, is the C-terminal residue, the fragment ion distribution obtained from this peptide differs dramatically from those obtained with arginine-terminated peptides. Only three weak $x$ type ions are observed, along with 2 -type ions. An extensive series of $y$-type ions is observed, along with several $b$-type ions. The photodissociation fragments are still different from those generated by PSD (Figure 6b) and low-energy CID (Figure 6c), although there is more similarity than there had been with arginine-containing peptides. High-energy CID (Figure 6d) produces $y$-type ions, and some $a$ - and $b$-type fragments are also present, but no $x$ ions are observed. When this peptide is modified via a $1 \mathrm{~h}$ guanidination reaction [39], converting the lysine into homoarginine, the photodissociation spectrum (Figure 6e) resembles that of an arginine-containing peptide, with primarily $x, v$, and $w$ ions accompanied by a few $y$ ions.

\section{Photodissociation Efficiency}

Evaluation of the utility of any fragmentation technique requires consideration of how effectively precursor ions are converted into fragments. The efficiency with which peptide ions photodissociate certainly depends on the intensity of the $157 \mathrm{~nm}$ light. It was of interest to study this efficiency using the fluences that were employed to generate our photofragmentation TOF-TOF spectra. Two peptides were investigated: FSWGAEGQR and ALELFR. Experimental conditions were optimized as described above to ensure accurate precursor peak areas, and five replicate experiments were performed with each molecule. While maximizing the information available from fragment ions is the goal of tandem mass spectrometry experiments, ion detection efficiency of the apparatus varies somewhat with mass. Therefore, instead of directly comparing daughter and precursor ion signals, we measured the extent of precursor ion depletion caused by laser irradiation. The average depletion obtained for the two molecules was $25 \pm 3 \%$ for ALELFR and $28 \pm 3 \%$ for FSWGAEGQR.

\section{Discussion}

The most striking feature of peptide ion photodissociation using $157 \mathrm{~nm}$ light is the consistent formation of $x$ or a-type ions, depending on whether an arginine residue is located near the $\mathrm{C}$ - or N-terminus of the peptide. In contrast, post-source decay and low-energy collision induced dissociation tend to produce a more random distribution of thermal $y-, b-$, and $a$-type ions that is less dependent on the location of basic sites. There is some similarity between photodissociation at $157 \mathrm{~nm}$ and high-energy collisional dissociation. Some of the $a-, d-, v,-$ and $w$-type ions observed after $157 \mathrm{~nm}$ photodissociation are present in high-energy CID spectra, but two features of the data indicate that $157 \mathrm{~nm}$ photodissociation occurs via a different mechanism.
First, the abundance of $x$-type ions and the contiguous series of $x$ ions that are observed in $157 \mathrm{~nm}$ photodissociation of peptides with C-terminal arginine residues are unique. Second, while photodissociation and highenergy CID of peptides with $\mathrm{N}$-terminal arginine yield MS/MS spectra that are somewhat similar, careful examination of the photodissociation results shows that several $a$-type ions are $1 \mathrm{Da}$ heavier than standard $a$ ions. The structure associated with these fragments provides important evidence to support a different mechanism.

\section{$x$-Type Ions}

While the standard nomenclature for peptide fragmentation identifies six major backbone fragment types, many of these fragments are not commonly detected. In experiments using low-energy activation methods, $y$-, $b-$, and $a$-type ions are primarily observed. With higher energy excitation, the major fragments are $v-, w-$, and $d$-type ions [41]. Their production involves cleavages of both the peptide backbone and the adjacent amino acid side-chain. Our high-energy collisional activation experiments were designed to allow direct comparison with $157 \mathrm{~nm}$ photodissociation. Using average parameters from our study, it can be calculated that collisions between $1000 \mathrm{~m} / \mathrm{z}$ peptide ions and air molecules (assumed to be $\mathrm{N}_{2}$ ) with $2 \mathrm{keV}$ laboratory frame kinetic energy have a center of mass collision energy of $54 \mathrm{eV}$ [11]. It has been estimated that in this energy range, only $15 \%$, or $8.1 \mathrm{eV}$ of the collision energy, is converted to internal excitation of the ion [42]. This value is quite comparable to the $7.9 \mathrm{eV}$ photon energy of $157 \mathrm{~nm}$ light. Nevertheless, very few $x$-type fragments are observed in the high-energy CID experiment. Both our results and those published by other groups [14, 23, 37, 41, 43-45] indicate that $x$-type ions are not commonly observed when high-energy activation techniques are used. Both the present results and those we have previously published [9] demonstrate the propensity of $157 \mathrm{~nm}$ photodissociation to generate $x$ ions from peptides having C-terminal arginine residues. This propensity provides the first evidence that the fragmentation induced by $157 \mathrm{~nm}$ light is not simply a result of the total energy deposited into the molecule, but instead the light induces a different fragmentation process.

\section{a-Type Ions}

While the $x$-type ions observed from peptides having C-terminal arginine residues are unusual, the overall distribution of fragment ions formed when peptides having N-terminal arginines undergo $157 \mathrm{~nm}$ photodissociation is less unique. The $a$ - and $d$ - type ions that dominate the photodissociation spectra appear to be similar to those observed in our high-energy CID experiments, and they have been commonly observed in other high-energy activation studies [41]. Expanded views of some of the fragment peaks, shown in Figure 
(a)

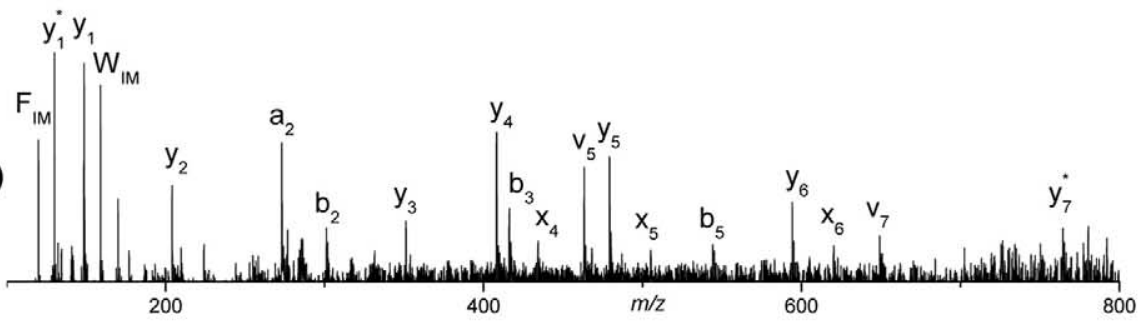

(b)

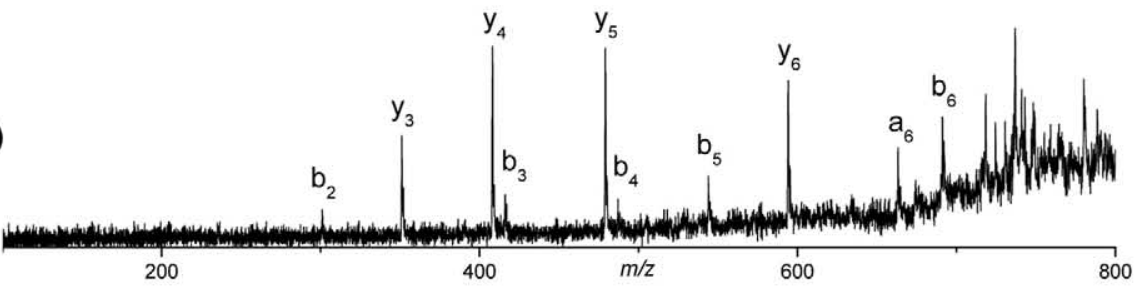

(c)

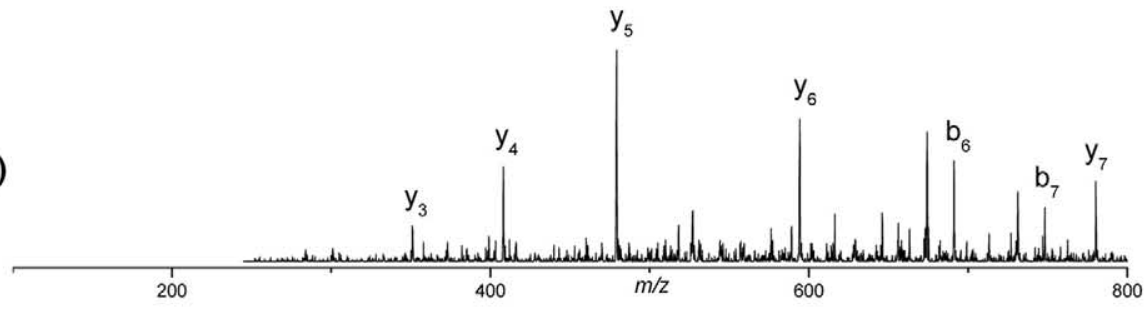

(d)

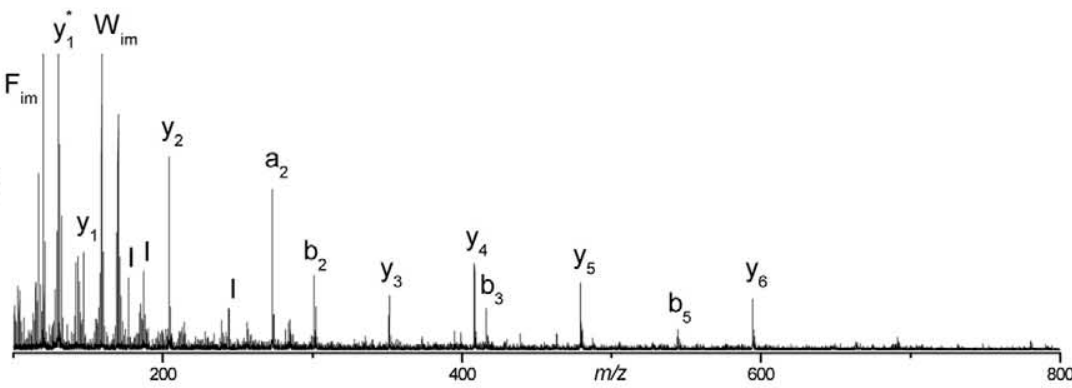

(e)

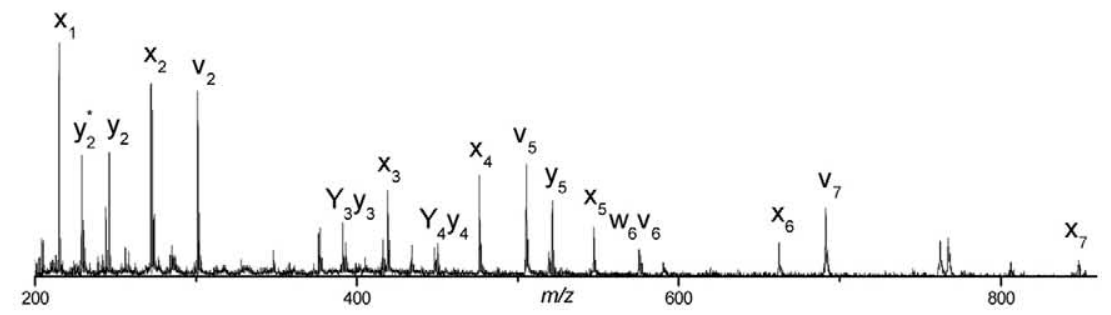

Figure 6. Tandem mass spectra of the singly charged Carboxypeptidase A tryptic peptide NWDAGFGK obtained by (a) $157 \mathrm{~nm}$ photodissociation, (b) post-source decay, (c) ion trap CID, (d) $2 \mathrm{keV}$ CID, (e) guanidinated $157 \mathrm{~nm}$ photodissociation. 
7, reveal unusual isotope distributions. Experimental peaks appear as solid lines, and calculated isotopic distributions are shown as dotted lines. No subtraction was performed on these spectra to avoid perturbing the isotope ratios. The results in Figure 7a and b show that with photodissociation, peaks 1 Da heavier than the $a$-type ions $\left(a_{n}+1\right.$ ions) are sometimes significantly more intense than would be expected based on the calculated isotopic distribution. Note that for all of the larger $a$-type fragments not shown here, the $a+1$ intensities match the predicted isotopic distribution. PSD data obtained for fragments of similar mass from the same molecule are shown in Figure 7c. They exhibit predicted isotope distributions, as do all PSD fragments, indicating that the unusual distribution must be associated with the photodissociation process and is not an artifact of the mass spectrometry. The mass resolution obtained for PSD fragments is somewhat lower than that obtained for photofragments. Post-source decay fragments are primarily formed within the flight tube, while photofragments are formed within the second stage source. Nonideal electric fields may exist between the first stage flight tube and the second stage source of the instrument, particularly around the ion gate. These fields would influence the lighter and therefore lower kinetic energy PSD fragments more strongly than the intact precursor and would have little influence on the fragments formed later by photodissociation of the intact precursor.

The structure shown on the left in Scheme 2 has a molecular weight $1 \mathrm{Da}$ heavier than a standard $a$-type ion. It is an odd-electron ion, and we propose that it forms through a homolytic radical cleavage of the $\alpha$-carbon carbonyl-carbon bond. This cleavage would yield two radical products, one of which would retain the charge proton, and the other would have no charge. The complementary structure that could form if the charge were retained at the C-terminus is also shown.

Biemann and coworkers have attributed the origin of $d$ - and $a$-type ions to $a_{n}+1$ ions by precursor scanning experiments on a four-sector instrument. However, in their study, the abundance of intact $a+1$ ions was found to be negligible [14]. The intensities of $a_{n}+1$ ions in the tandem TOF high-energy CID data shown in Figure $7 \mathrm{~d}$ and e are intermediate between the sector and photodissociation experiments. The experimental and predicted isotope patterns are very close to each other with the exception of two ions: $a_{1}$ from the first and $a_{2}$ from the second peptide, providing evidence that some $a+1$ ions are formed in high-energy CID, although a smaller number than with photodissociation. We have not observed significant radical ion yields by photodissociation or high-energy CID for our peptides that produce $x$-type ions. Nevertheless, the increased abundance of the $a_{n}+1$ radical ions suggests that they are intermediates directly formed in the $157 \mathrm{~nm}$ photodissociation experiment.

\section{Photodissociation}

We have shown that $157 \mathrm{~nm}$ photodissociation of peptides yields two unusual ion types: $a+1$ and $x$ ions. While only the $a+1$ ions provide direct evidence of radical photolysis, the peptide backbone must be cleaved at the same location, between $\mathrm{C} \alpha$ and the carbonyl-carbon, to form either fragment type. Therefore, likely the same radical photolysis occurs as the initial step in the formation of $a+1$ and $x$ fragments. While information available about the vacuum ultraviolet photochemistry of molecules as large as peptides is quite limited, there is some evidence that such a process is possible. Based on studies described earlier [33-35], one possible chromophore for absorption of a $157 \mathrm{~nm}$ photon by a peptide was shown to be the backbone amide. The Norrish Type I photoreaction is a wellcharacterized reaction for small aldehydes and ketones $[46,47]$. The reaction has also been observed in small amides, such as acetamide [48]. This process would be expected to lead to homolytic radical cleavage between the $\alpha$-carbon and carbonyl carbon. For peptide ions, these products would be radical $a+1$ or $x+1$ ions.

\section{Secondary Fragmentation}

$157 \mathrm{~nm}$ photodissociation produces several distinct types of fragments. The $a+1$ ions described above are directly formed in the initial homolytic cleavage. Secondary fragmentation processes must be invoked to explain the appearance of the primary observed species, even electron $a$ - and $x$-type ions. The latter are formed from radical precursors through similar processes involving $\mathrm{H}$ atom elimination. The formation of $d-, v-$, or $w$-type ions from the radical intermediate involves cleavage within the amino acid side-chain adjacent to the photolysis site.

The mechanisms by which $a+1$ and $x+1$ ions undergo radical elimination of $\mathrm{H}$ atom to form the detected even-electron $a$ and $x$ ions are shown in Scheme 3. To form an even-electron $a$ ion from an $a+1$ precursor, an $\mathrm{H}$ atom is eliminated from the $\beta$-carbon and a double-bond forms between the $\alpha$ - and $\beta$-carbons. Alternatively, the hydrogen at the amide nitrogen could be eliminated. However, in several cases that we have studied (e.g., Substance P, Figure 4), $a$ ions resulting from cleavage at glycine residues are missing from the spectrum. Glycine is the only amino acid that does not have a hydrogen attached to a $\beta$-carbon, implicating the importance of this particular $\mathrm{H}$ atom for the generation of $a$-type fragments. The formation of $x$-type ions from $x+1$ precursors is expected to follow a similar process in which an $\mathrm{H}$ atom is eliminated from the backbone amide, forming a double-bond between the carbonylcarbon and amide nitrogen. The structures we have drawn for the $a$ and $x$ fragments differ slightly from the standard forms, as the charge does not need to be at the fragmentation site for the homolytic cleavage to occur. It is instead shown near the N- or C-terminal arginine 

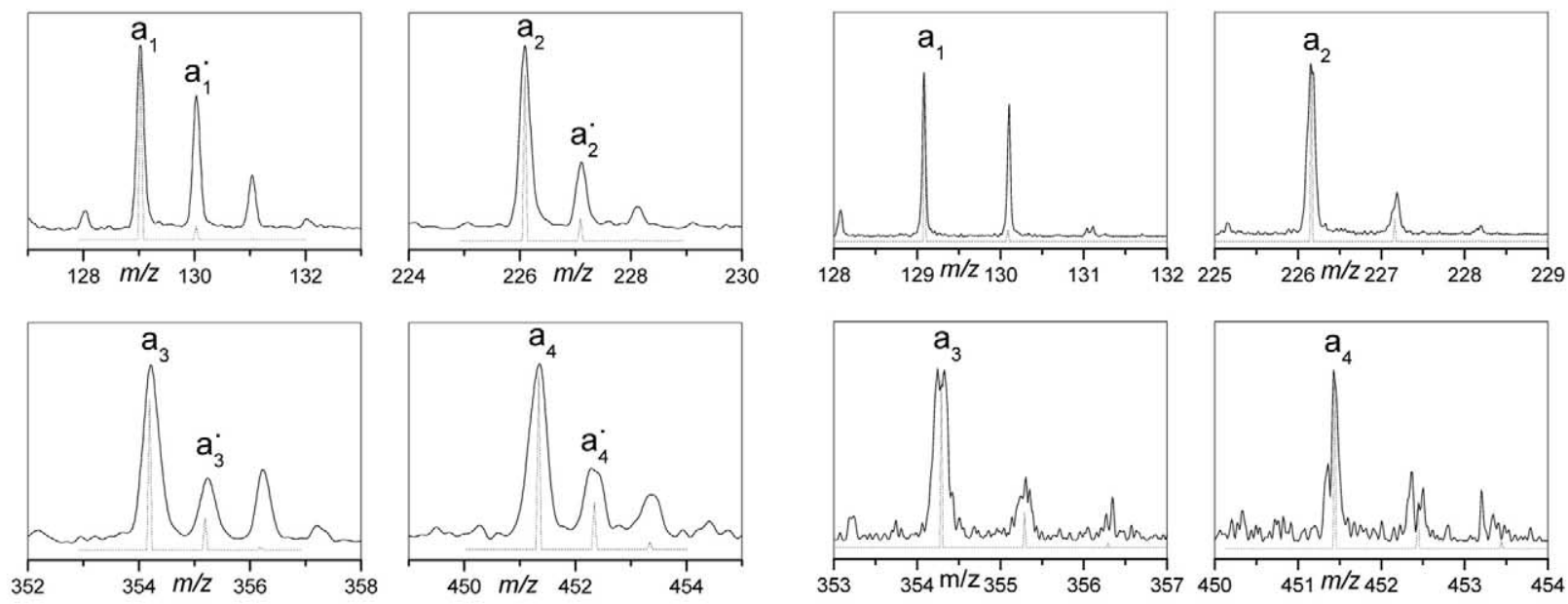

(a)

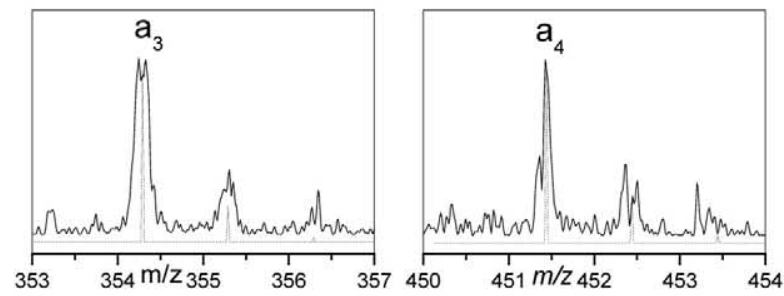

(d)
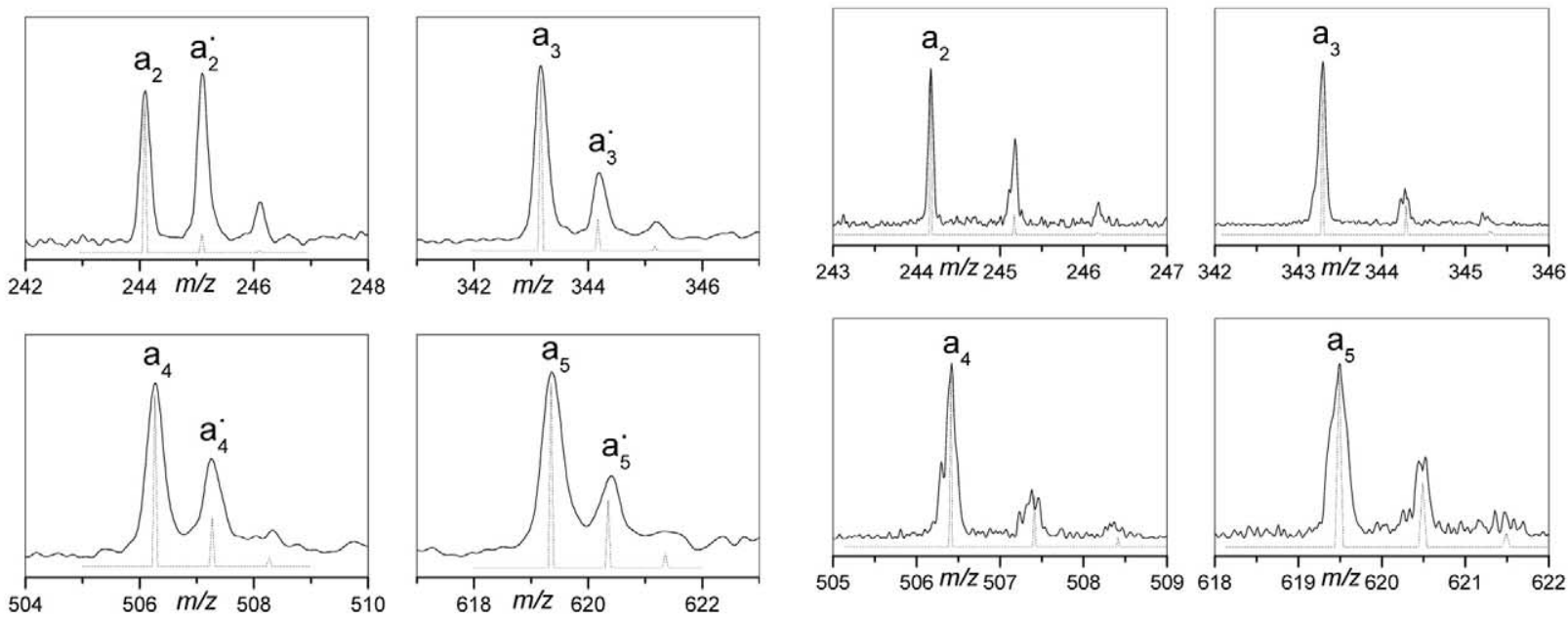

(b)

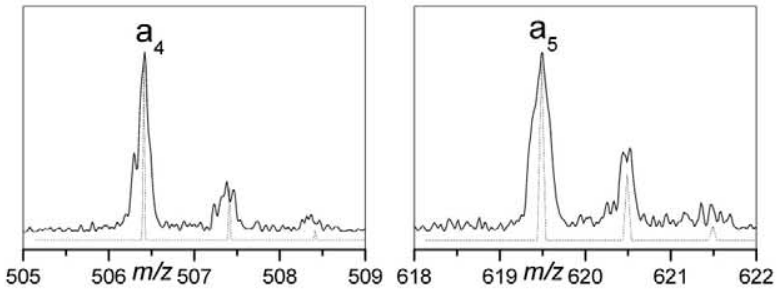

(e)
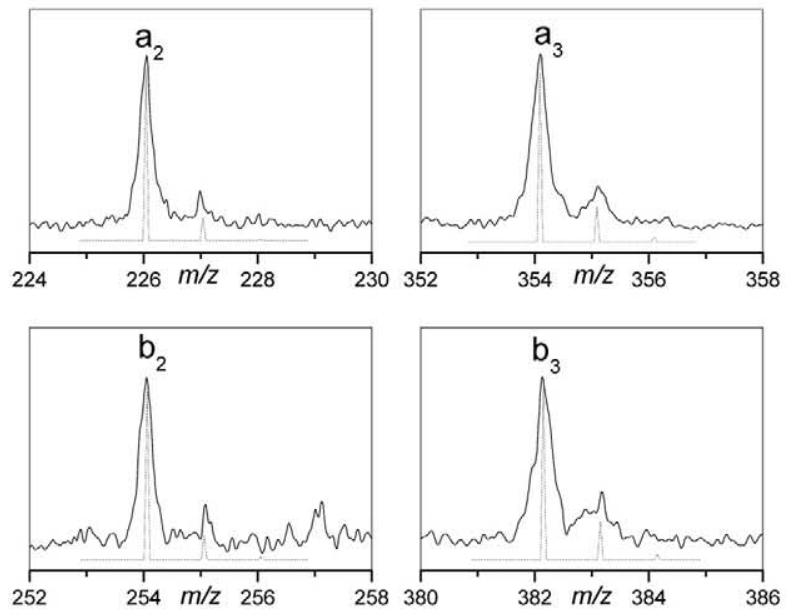

(c)

Figure 7. Expanded views of single peaks from (a) photodissociation of RPKPQQFFGLM- $\mathrm{NH}_{2} ;(\mathbf{b})$ photodissociation of DRVYIHPF; (c) PSD of RPKPQQFFGLM-NH ${ }_{2}$; (d) $2 \mathrm{keV} \mathrm{CID} \mathrm{of} \mathrm{RPKPQQFFGLM-}$ $\mathrm{NH}_{2}$; and (e) $2 \mathrm{keV}$ CID of DRVYIHPF. Solid lines are experimental data, dashed lines are predicted isotope distributions. Subtraction of the PSD spectrum was not performed for (a) and (b). The intensity scales are normalized to the largest peak shown. 

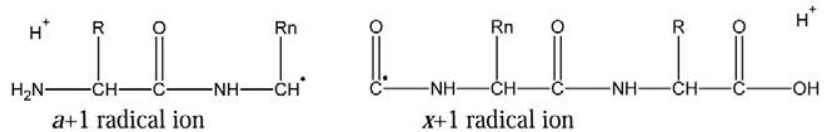

Scheme 2. Radical products of homolytic cleavage of the CXcarbonyl bond

residue. Our structures, however, have the same masses as the conventional $a$ - and $x$-type ions [14].

$d-, v$, and $w$-type ions are the remaining commonly observed fragment types in $157 \mathrm{~nm}$ photodissociation experiments. They are generally known as "highenergy" fragments, since cleavage of two bonds is required, and the threshold energies for these dissociation channels are higher. $d$ - and $w$-type fragments can be used to distinguish the isobaric amino acids leucine and isoleucine [23]. Mechanisms for the formation of these fragments in high-energy collisional activation experiments have been previously described by the Biemann group. They showed that primarily $y$ but occasionally $x+1$ precursor ions can generate $v$-type products [14], while $z+1$ precursor ions yielded $w$-type products [23]. The observation of $x+1$ precursor ions is of particular relevance to this study. While we propose the same intermediate, our observation of many evenelectron $x$ ions suggests that we have a larger $x+1$ population than is formed in high-energy CID experiments. Processes that would produce our observed $d-$, $v$-, and w-type fragments are summarized in Scheme 4. Radical elimination via partial side-chain loss, retaining at least the $\beta$-carbon, leads to $d$-type fragments. Both $\mathrm{CO}$ and a complete radical side-chain adjacent to the cleavage site are lost from $x+1$ precursor ions to form $v$ ions. Loss of $\mathrm{CONH}$ and a radical fragment of the side-chain from the $x+1$ precursors forms $w$ ions.

In summary, we have proposed that photolysis of the $\alpha$-carbon carbonyl-carbon bond is the initial step in the photodissociation of peptide ions, and that a variety of secondary processes lead to the observed fragments. These processes range from the detection of the $a+1$ radical ion from some small fragments having $\mathrm{N}$ terminal basic groups to the multiple secondary cleavages required to form $w$ fragments. Radical elimination is more efficient for large $a+1$ and all $x+1$ intermediates, but several different elimination processes have been observed to yield either the $a$ - and $x$-type fragments through $\mathrm{H}$ atom elimination or $d-, v-$, and $w$-type fragments through a variety of side-chain eliminations. While the exact reasons why this range of processes is observed cannot be determined from our experiments, the internal energy of the ion both before and after photodissociation is likely to play an important role in determining what subsequent processes can occur and therefore what product ions are observed.

MALDI ionization is known to impart significant internal excitation to analyte ions that enables their metastable decomposition (i.e., post-source decay [49, 50]. Efforts have been made to measure and control internal excitation, and a large number of factors have been found to influence its extent [51-53], including the choice of matrix and additives [45, 54,55], ionization laser wavelength and fluence [56], and matrix crystal structure [57]. While it is possible to obtain reduced internal energies by performing MALDI with threshold laser powers, the present studies were performed using somewhat higher laser powers to improve the precursor ion yield. The post-source decay results in Figures 2, 3,4 , and 6 show that a significant number of ions have sufficient internal energies to undergo fragmentation while in the first flight tube. It requires little extrapolation to suggest that even those ions that do not undergo PSD fragmentation must be vibrationally excited before photodissociation.

Absorption of a single $7.9 \mathrm{eV}$ photon by a peptide ion imparts significantly more energy than the 3 to $4 \mathrm{eV}$ required to cleave the $\alpha$-carbon carbonyl-carbon bond. This excess energy, after photolysis along with the excitation imparted during the MALDI ionization process, can serve as the driving force for secondary processes. The availability of considerable activation energy facilitates a range of different secondary processes.

While arginine-containing peptides tend to yield the $x, v, w, a$, and $d$ ions, small numbers of other types of fragments are occasionally present in our photodissociation spectra. For example, Figure 2a contains $3 y$-type ions, Figure $3 a$ contains one $z-$, one $y$ - and one $y^{*}$ ion, and Figure 4 a contains one $b$ - and one $c$-type ion. It is important to note that these are all $C$-terminal fragments if the precursor possessed a C-terminal arginine or N-terminal fragments if arginine was at or near the

(a)

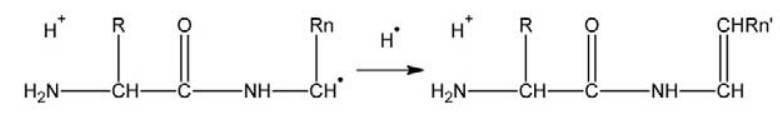

a+1 precursor ion a a

(b)

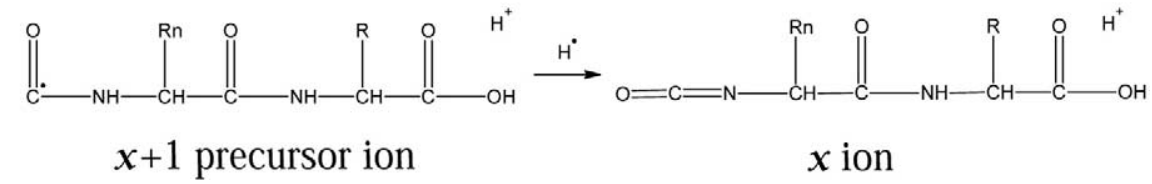

Scheme 3. Radical elimination to yield even-electron products 


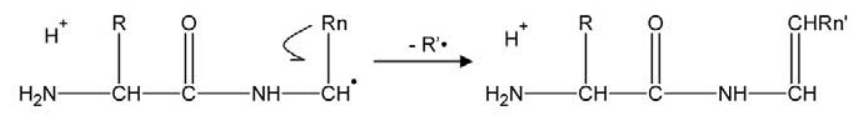

(a) a+1 precursor ion

$d$ ion

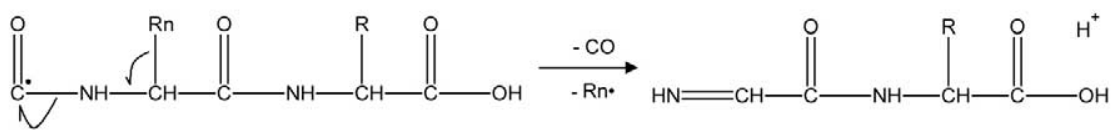

(b)

$\boldsymbol{X}+1$ precursor ion

$v$ ion

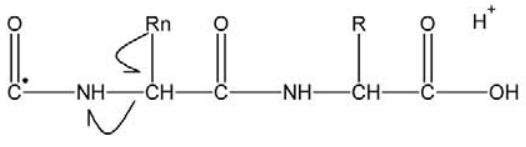

(c) $x+1$ precursor ion
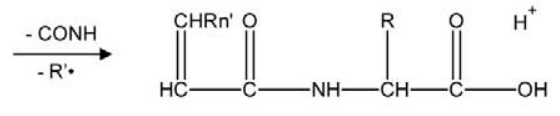

$w$ ion

Scheme 4. Generation of side-chain loss fragments from radical precursor ions.

$\mathrm{N}$-terminus. We observe no evidence of charge mobility in these $157 \mathrm{~nm}$ peptide ion photodissociation experiments. Since background subtraction has been performed, removing the contribution of post-souce decay fragments from the photodissociation spectrum, all of these fragments must be photochemical products, although alternative processes besides the homolytic cleavage of the $\alpha$-carbon carbonyl-carbon bond may be involved.

We described a mechanism above in which the formation of $d-, v-$, and $w$-type ions is driven by the total vibrational excitation resulting from both the MALDI and photodissociation processes. Side-chain cleavages adjacent to the photodissociation site appear to be the major products. The formation of $y$-type ions from peptides having C-terminal arginine residues is likely to be promoted by the same activation process. A large, odd- or even-electron $x$ ion formed by photolytic cleavage near the $\mathrm{N}$-terminus of the peptide presumably serves as an intermediate. If this ion has sufficient internal energy, it should be able to undergo additional fragmentation. The mobile proton mechanism is one well-known process by which secondary fragments such as C-terminal $y$-type ions could easily form [12]. Should the charge remain on the $\mathrm{N}$-terminal secondary fragment, an internal fragment would be formed.

The mechanism just outlined need not describe every photochemical pathway resulting from absorption of $157 \mathrm{~nm}$ light by a peptide ion. The amide chromophore is the best-characterized site for absorption at this wavelength, and its expected photochemistry is consistent with our major observations. Molecules as large as peptides have other possible chromophores, especially when amino acid side chains are considered. Depending on the residues involved, it is therefore likely that other chromophores associated with different extinction coefficients can lead to different excited electronic states and therefore different photochemical fragmentation channels.

\section{Role of Arginine}

The side-chain of arginine has the highest gas-phase basicity [58] among all the amino acids, making it the most favorable site for protonation of a peptide ion. It has been shown that the threshold dissociation energies of peptide ions correlate with the gas-phase basicity of the protonation site, and arginine-containing peptides have the highest dissociation thresholds [59]. The mobility of a proton from a basic site to the peptide backbone apparently facilitates fragmentation [12]. The PSD and CID spectra obtained from arginine-containing peptides, particularly those in Figures 2 and 3, contain both $\mathrm{N}$ - and C-terminal fragments, suggesting that a proton does not remain sequestered but is involved in the fragmentation process. However, in $157 \mathrm{~nm}$ photodissociation experiments with arginine-terminated peptides, the charge remains on the arginine-containing fragment. It makes sense that the charge remains sequestered by arginine if the fragmentation involves a very rapid homolytic radical cleavage. Lysine has a significantly lower gas-phase basicity than arginine, which gives lysine-containing peptides (Figure 6a) a lower energy threshold for proton mobilization. The charge 
proton is probably mobilized before the photoexcitation event due to energy imparted during the MALDI process. This leads to the observed scrambling of the charge site in the photodissociation spectrum and the occurrence of charge-induced secondary processes. Methods to increase the gas-phase basicity of lysine by conversion to homoarginine are available [39,60]. Similar to arginine-terminated peptides, these modified peptides yield a nearly full series of $x$ ions together with multiple $v$-and $w$-type ions (Figure 6e).

\section{Is the Initial Cleavage Nonergodic?}

The mechanism we have outlined for $157 \mathrm{~nm}$ photodissociation involves homolytic radical cleavage via a Norrish Type I process as its initial step. In small molecules, this type of cleavage is known to occur from an $n \pi^{*}$ electronic state. Intramolecular vibrational redistribution (IVR) is predicted by RRKM theory to occur more quickly than dissociation processes for relatively large molecules [28]. By using acetone as a prototype molecule, Zewail and coworkers have observed that the Norrish Type I cleavage of acetone occurs via a two step process, with the two $\alpha$-carbon carbonyl-carbon bonds cleaved separately. Upon excitation by two photon absorption at 307 or $280 \mathrm{~nm}$ in their femtosecond mass spectrometry experiment, acetone is excited to its $n-4 s$ Rydberg state. The first $\alpha$-cleavage occurs on a time scale (50 fs) shorter than a vibrational period, indicating $\sigma^{*}$ promotion is involved and IVR is circumvented. The second cleavage occurs on a longer timescale, suggesting that electronic to vibrational relaxation could take place before this cleavage [61]. Subsequent femtosecond experiments on a series of cyclic ketones have shown only a small dependence of Norrish Type I dissociation rates on ring size. The difference between the experimentally determined rates and RRKM predictions is in the range of two to four orders of magnitude [62]. These results indicate that IVR does not precede the bond cleavage reaction. The dissociation is nonergodic and does not involve statistical energy distribution among all modes of the molecule.

We have presented evidence that radical cleavage of the $\alpha$-carbon carbonyl-carbon bond via a Norrish Type I cleavage can occur in peptides. Absorption of a $157 \mathrm{~nm}$ photon $(7.9 \mathrm{eV})$ can impart an energy comparable to the two photons in Zewail's ketone experiments $(8-8.8 \mathrm{eV})$. Nonergodic reactions for larger molecules, for example, electron capture dissociation of multiply charged peptides or proteins, have also been postulated [24]. We suggest that the nonergodic behavior observed in studies of small molecule photodissociation via Norrish Type I processes may also occur when this cleavage is induced in peptide ions by $157 \mathrm{~nm}$ light. After the initial radical cleavage, some excess internal energy is available that redistributes throughout the entire radical ion, inducing secondary processes that form the observed ions. Studies of larger peptides and proteins are planned to determine whether their increased vibra- tional state densities increase the IVR rate sufficiently to inhibit the radical cleavage and favor thermal ion fragmentation processes.

\section{Depletion Efficiency}

To obtain maximum sensitivity in a tandem mass spectrometry experiment, high fragmentation efficiencies are desirable. With the current experimental configuration, depletion rates of $\sim 27 \%$ have been obtained. These are similar to early ECD results [24], although not as high as those recently reported for ECD [63] and ETD [25]. The efficiency observed in these studies does not reflect an inherent limitation of the technique, and is likely to improve if a more powerful light source is used, or if the photodissociation laser is better focused onto the ion packet. The intensities of our observed PSD and photodissociation fragment ions are generally comparable. While photodissociation of PSD products can occur, the yield of these secondary daughter ions should be relatively low.

\section{Conclusions}

The observation of small radical precursor ions formed by $157 \mathrm{~nm}$ photodissociation of peptide ions with arginine at or near the $\mathrm{N}$-terminus strongly supports the proposed mechanism that photolytic radical cleavage takes place as the initial step upon photoexcitation, and subsequent radical elimination processes form the observed ions. $a$-type ions result from elimination of a hydrogen atom from the corresponding radical precursor ion. Formation of predictable $x$ ions with nearly full sequence coverage from peptide ions terminated with arginine or guanidinated lysine makes $157 \mathrm{~nm}$ photodissociation a potentially promising technique to fragment peptides obtained by digestion of proteins with trypsin.

\section{Acknowledgments}

This work has been supported by NIH grant GM61336, NSF grant CHE00945479, and the Indiana Genomics Initiative.

\section{References}

1. Hunt, D. F.; Bone, W. M.; Shabanowitz, J.; Rhodes, J.; Ballard, J. M. Sequence analysis of oligopeptides by secondary ion/ collision activated dissociation mass spectrometry. Anal. Chem. 1981, 53, 1704-1706.

2. Cantin, G. T.; Yates, J. R. III. Strategies for shotgun identification of post-translational modifications by mass spectrometry. J. Chromatogr. A 2004, 1053, 7-14.

3. Price, W. D.; Schnier, P. D.; Williams, E. R. Tandem mass spectrometry of large biomolecule ions by blackbody infrared radiative dissociation. Anal. Chem. 1996, 68, 859-866.

4. Zimmerman, J. A.; Watson, C. H.; Eyler, J. R. Multiphoton ionization of laser-desorbed neutral molecules in a Fourier transform ion cyclotron resonance mass spectrometer. Anal. Chem. 1991, 63, 361-365. 
5. Bowers, W. D.; Delbert, S. S.; Hunter, R. L.; McIver, R. T., Jr. Fragmentation of oligopeptide ions using ultraviolet laser radiation and Fourier transform mass spectrometry. J. Am. Chem. Soc. 1984, 106, 7288-7289.

6. Martin, S. A.; Hill, J. A.; Kittrell, C.; Biemann, K. Photoninduced dissociation with a four-sector tandem mass spectrometer. J. Am. Soc. Mass Spectrom. 1990, 1, 107-109.

7. Barbacci, D. C.; Russell, D. H. Sequence and side-chain specific photofragment $(193 \mathrm{~nm})$ ions from protonated Substance P by matrix-assisted laser desorption ionization time-of-flight mass spectrometry. J. Am. Soc. Mass Spectrom. 1999, 10, 1038-1040.

8. Oh, J. Y.; Moon, J. H.; Kim, M. S. Tandem time-of-flight mass spectrometer for photodissociation of biopolymer ions generated by matrix-assisted laser desorption ionization (MALDITOF-PD-TOF) using a linear-plus-quadratic potential reflectron. J. Am. Soc. Mass Spectrom. 2004, 15, 1248-1259.

9. Thompson, M. S.; Cui, W.; Reilly, J. P. Fragmentation of singly-charged peptides by photodissociation at $\lambda=157 \mathrm{~nm}$. Angew. Chem. Int. Ed. 2004, 43, 4791-4794.

10. Williams, E. R.; Henry, K. D.; McLafferty, F. W.; Shabanowitz, J.; Hunt, D. F. Surface-induced dissociation of peptide ions in Fourier-transform mass spectrometry. J. Am. Soc. Mass Spectrom. 1990, 1, 413-416.

11. Sleno, L.; Volmer, D. A. Ion activation methods for tandem mass spectrometry. J. Mass. Spectrom. 2004, 39, 1091-1112.

12. Wysocki, V. H.; Tsaprailis, G.; Smith, L. L.; Breci, L. A. Mobile and localized protons: A framework for understanding peptide dissociation. J. Mass Spectrom. 2000, 35, 1399-1406.

13. Roepstorff, P.; Fohlman, J. Proposal for a common nomenclature for sequence ions in mass spectra of peptides. Biomed. Mass Spectrom. 1984, 11, 601.

14. Johnson, R. S.; Martin, S. A.; Biemann, K. Collision-induced fragmentation of $(M+H)+$ ions of peptides. Side chain specific sequence ions. Int. J. Mass Spectrom. Ion Processes 1988, $86,137-154$

15. Jensen, N. J.; Tomer, K. B.; Gross, M. L. Gas-phase ion decompositions occurring remote to a charge site. J. Am. Chem. Soc. 1985, 107, 1863-1868.

16. Gross, M. L. Charge-remote fragmentations: Method, mechanism, and applications. Int. J. Mass Spectrom. Ion Processes 1992, 118/119, 137-165.

17. Cheng, C.; Gross, M. L. Applications and mechanisms of charge-remote fragmentation. Mass Spectrom. Rev. 2000, 19, $398-420$.

18. Summerfield, S. G.; Dale, V. C. M.; Despeyrous, D. D.; Jennings, K. R.Charge-remote losses of small neutrals from protonated and Group I metal-peptide complexes of peptides. Eur. J. Mass Spectrom. 1995, 1, 183-194.

19. Zaia, J.; Biemann, K. Comparison of charged derivatives for high energy collisional-induced dissociation tandem mass spectrometry. J. Am. Soc. Mass Spectrom. 1995, 6, 428.

20. Sadagopan, N.; Watson, J. T. Investigation of the tris(trimethoxyphenyl)phosphonium acetyl charged derivatives of peptides by electrospray ionization mass spectrometry and tandem mass spectrometry. J. Am. Soc. Mass Spectrom. 2000, 11, 107-119.

21. Huang, Z.-H.; Wu, J.; Roth, K. D. W.; Yang, Y.; Gage, D. A.; Watson, J. T. A. picomole-scale method for charge derivatization of peptides for sequence analysis by mass spectrometry. Anal. Chem. 1997, 69, 137-144.

22. Liao, P.-C.; Huang, Z.-H.; Allison, J. Charge remote fragmentation of peptides following attachment of a fixed positive charge: A matrix-assisted laser desorption/ionization postsource decay study. J. Am. Soc. Mass Spectrom. 1997, 8, 501-509.

23. Johnson, R. S.; Martin, S. A.; Biemann, K.; Stults, J. T.; Watson, J. T. Novel fragmentation processes of peptides by collisioninduced decomposition in a tandem mass spectrometer: Dif- ferentiation of leucine and isoleucine. Anal. Chem. 1987, 59, 2621-2625.

24. Zubarev, R. A.; Kelleher, N. L.; McLafferty, F. W. Electron capture dissociation of multiply charged protein cations. A nonergodic process. J. Am. Chem. Soc. 1998, 120, 3265-3266.

25. Syka, J. E. P.; Coon, J. J.; Schroeder, M. J.; Shabanowitz, J.; Hunt, D. F. Peptide and protein sequence analysis by electron transfer dissociation mass spectrometry. Proc. Natl. Acad. Sci. U.S.A. 2004, 101, 9528-9533.

26. Zubarev, R. A.; Kruger, N. A.; Fridriksson, E. K.; Lewis, M. A.; Horn, D. M.; Carpenter, B. K.; McLafferty, F. W. Electron capture dissociation of gaseous multiply-charged proteins is favored at disulfide bonds and other sites of high hydrogen atom affinity. J. Am. Chem. Soc. 1999, 121, 2857-2862.

27. Breuker, K.; Oh, H.; Lin, C.; Carpenter, B. K.; McLafferty, F. W. Nonergodic and conformational control of the electron capture dissociation of protein cations. Proc. Natl. Acad. Sci. U.S.A. 2004, 101, 14011-14016.

28. Hu, Y.; Hadas, B.; Davidovitz, M.; Balta, B.; Lifshitz, C. Does IVR take place prior to peptide ion dissociation? J. Phys. Chem. A 2003, 107, 6507-6514.

29. Thompson, M. S.; Cui, W.; Reilly, J. P. MALDI photodissociation TOF-TOF mass spectrometry. Proceedings of the 51st ASMS Conference on Mass Spectrometry and Allied Topics; Montreal, Quebec, June, 2003.

30. Williams, E. R.; Furlong, J. J. P.; McLafferty, F. W. Efficiency of collisionally-activated dissociation and 193-nm photodissociation of peptide ions in Fourier transform mass spectrometry. J. Am. Soc. Mass Spectrom. 1990, 1, 289-294.

31. Oh, J. Y.; Moon, J. H.; Kim, M. S. Sequence- and site-specific photodissociation at $266 \mathrm{~nm}$ of protonated synthetic polypeptides containing a tryptophanyl residue. Rapid Commun. Mass Spectrom. 2004, 18, 2706-2712.

32. Robin, M. Higher excited states of polyatomic molecules, Vol. II.; Academic Press: Orlando, FL, 1975, p. 139.

33. Peterson, D. L.; Simpson, W. T. Polarized electronic absorption spectrum of amides with assignments of transitions. J. Am. Chem. Soc. 1957, 79, 2375-2382.

34. Clark, L. B. Polarization assignments in the vacuum UV spectra of the primary amide, carboxyl, and peptide groups. J. Am. Chem. Soc. 1995, 117, 7974-7986.

35. Woody, R. W.; Koslowski, A. Recent developments in the electronic spectroscopy of amides and a-helical polypeptides. Biophys. Chem. 2002, 101/102, 535-551.

36. Suckau, D.; Resemann, A.; Schuerenberg, M.; Hufnagel, P.; Franzen, J.; Holle, A. A novel MALDI LIFT-TOF/TOF mass spectrometer for proteomics. Anal. Bioanal. Chem. 2003, 376, 952-965.

37. Medzihradszky, K. F.; Campbell, J. M.; Baldwin, M. A.; Falick, A. M.; Juhasz, P.; Vestal, M. L.; Burlingame, A. L. The characteristics of peptide collision-induced dissociation using a high-performance MALDI-TOF/TOF tandem mass spectrometer. Anal. Chem. 2000, 72, 552-558.

38. Christian, N. P.; Alexander, A. W.; Reilly, J. P. Design and evaluation of a low-cost, high-speed signal amplifier. Rev. Sci. Instrum. 2001, 72, 243-246.

39. Beardsley, R. L.; Reilly, J. P. Optimization of guanidination procedures for MALDI mass mapping. Anal. Chem. 2002, 74, 1884-1890.

40. Eng, J. K.; McCormack, A. L.; Yates, J. R. III. An approach to correlate tandem mass spectral data of peptides with amino acid sequences in a protein database. J. Am. Soc. Mass Spectrom. 1994, 5, 976-989.

41. Papayannopoulos, I. A. The interpretation of collision-induced dissociation tandem mass spectra of peptides. Mass Spectrom. Rev. 1995, 14, 49-73. 
42. Meroueh, O.; Hase, W. L. Collisional activation of small peptides. J. Phys. Chem. A 1999, 103, 3981-3990.

43. Despeyroux, D.; Wright, A. D.; Jennings, K. R. Comparison of collision-induced dissociation and surface induced dissociation mass spectra of peptides obtained using a four-sector mass spectrometer. Int. J. Mass Spectrom. Ion Processes 1993, 126, 95-99.

44. Medzihradszky, K. F.; Adams, G. W.; Burlingame, A. L.; Bateman, R. H.; Green, M. R. Peptide sequence determination by matrix-assisted laser desorption ionization employing a tandem double focusing magnetic-orthogonal acceleration time-of-flight mass spectrometer. J. Am. Soc. Mass Spectrom. 1996, 7, 1-10.

45. Stimson, E.; Truong, O.; Richter, W. J.; Waterfield, M. D.; Burlingame, A. L. Enhancement of charge-remote fragmentation in protonated peptides by high-energy CID MALDITOF-MS using "cold" matrices. Int. J. Mass Spectrom. Ion Processes 1997, 169/170, 231-240.

46. Norrish, R. G. W.; Crone, H. G.; Saltmarsh, O. D. Primary photochemical reactions. Part V. The spectroscopy and photochemical decomposition of acetone. J. Chem. Soc. 1934, $1456-1464$.

47. Turro, N. J. Modern molecular photochemistry; Benjamin/Cummings: Menlo Park, NJ 1978, pp. 528-532.

48. Bosco, S. R.; Cirillo, A.; Timmons, R. B. Photolysis of formamides and acetamides studies by electron spin resonance. J. Am. Chem. Soc. 1969, 91, 3140-3143.

49. Spengler, B.; Kirsch, D.; Kaufmann, R. Metastable decay of peptides and proteins in matrix-assisted laser-desorption mass spectrometry. Rapid Commun. Mass Spectrom. 1991, 5, 198-202.

50. Spengler, B.; Kirsch, D.; Kaufmann, R. Fundamental aspects of postsource decay in matrix-assisted laser desorption mass spectrometry. 1. Residual gas effects. J. Phys. Chem. 1992, 96, 9678-9684.

51. Gluckmann, M.; Karas, M. Special feature: Perspective-The initial ion velocity and its dependence on matrix, analyte, and preparation method in ultraviolet matrix-assisted laser desorption ionization. J. Mass Spectrom. 1999, 34, 467-477.

52. Zenobi, R.; Knochenmuss, R. Ion formation in MALDI mass spectrometry. Mass Spectrom. Rev. 1998, 17, 337-366.
53. Luo, G. H.; Marginean, I.; Vertes, A. Internal energy of ions generated by matrix-assisted laser desorption/ionization. Anal. Chem 2002, 74, 6185-6190.

54. Hettick, J. M.; McCurdy, K. L.; Barbacci, D. C.; Russell, D. H. Optimization of sample preparation for peptide sequencing by MALDI-TOF photofragment mass spectrometry. Anal. Chem. 2001, 73, 5378-5386.

55. Koster, C.; Castoro, J. A.; Wilkins, C. L. High-resolution matrix-assisted laser desorption ionization of biomolecules by Fourier-transform mass-spectrometry. J. Am. Chem. Soc. 1992, $114,7572-7574$.

56. Shufang, N.; Wenzhu, Z.; Chait, B. T. Direct comparison of infrared and ultraviolet wavelength matrix-assisted laser desorption/ionization mass spectrometry of proteins. J. Am. Soc. Mass Spectrom. 1998, 9, 1-7.

57. Strupat, K.; Karas, M.; Hillenkamp, F. 2,5-Dihydroxybenzoic acid: A new matrix for laser desorption-ionization mass spectrometry. Int. J. Mass Spectrom. Ion Processes 1991, 111, 89-102.

58. Harrison, A. G. The gas-phase basicities and proton affinities of amino acids and peptides. Mass Spectrom. Rev. 1997, 16, 201-217.

59. Dongre, A. R.; Jones, J. L.; Somogyi, A.; Wysocki, V. H. Influence of peptide composition, gas-phase basicity, and chemical modification on fragmentation efficiency: Evidence for the mobile proton model. J. Am. Chem. Soc. 1996, 118, 8365-8374.

60. Beardsley, R. L.; Karty, J. A.; Reilly, J. P. Enhancing the intensities of lysine-terminated tryptic peptide ions in matrixassisted laser desorption/ionization mass spectrometry. Rapid Commun. Mass Spectrom. 2000, 14, 2147-2153.

61. Kim, S. K.; Pedersen, S.; Zewail, A. H. Direct femtosecond observation of the transient intermediate in the alpha-cleavage reaction of $\left(\mathrm{CH}_{3}\right)_{2} \mathrm{CO}$ to $2 \mathrm{CH}_{3}+\mathrm{CO}$ : Resolving the issue of concertedness. J. Chem. Phys. 1995, 103, 477-480.

62. Diau, E. W.-G.; Herek, J. L.; Kim, Z. H.; Zewail, A. H. Femtosecond activation of reactions and the concept of nonergodic molecules. Science 1998, 279, 847-851.

63. Zubarev, R. A.; Horn, D. M.; Fridriksson, E. K.; Kelleher, N. L.; Kruger, N. A.; Lewis, M. A.; Carpenter, B. K.; McLafferty, F. W. Electron capture dissociation for structural characterization of multiply charged protein cations. Anal. Chem. 2000, 72, 563-573. 